\title{
Optimizing Parameters on Nanophotocatalytic Degradation of Ibuprofen Using UVC/ZnO Processes by Response Surface Methodology
}

\author{
Noushin Rastkari ${ }^{1}$, Akbar Eslami ${ }^{2}$, Simin Nasseri ${ }^{1}$, Ehsan Piroti ${ }^{3}$, Anvar Asadi ${ }^{4 *}$ \\ ${ }^{1}$ Center for Water Quality Research, Institute for Environmental Research, \\ Tehran University of Medical Sciences, Tehran, Iran \\ ${ }^{2}$ Environmental and Occupational Hazards Control Research Center, Shahid Beheshti University \\ of Medical Sciences, Tehran, Iran \\ ${ }^{3}$ Department of Environmental Health Engineering, School of public Health, Student Research Office, \\ Shahid Beheshti University of Medical Sciences, Tehran, Iran \\ ${ }^{4}$ Research Center for Environmental Determinants of Health (RCEDH), Kermanshah University \\ of Medical Sciences, Kermanshah, Iran
}

Received: 19 June 2016

Accepted: 31 August 2016

\begin{abstract}
Due to the increasing importance of low-concentrated pollution of water resources, the photocatalytic decomposition of ibuprofen down to low ppm concentrations over zinc oxide catalyst has been studied. The aim of this work was to evaluate the degradation of the non-steroidal anti-inflammatory drug (NSAID) ibuprofen (IBP) using heterogeneous $\mathrm{ZnO}$ photocatalyst under UV-C irradiation. The photo catalyst was characterized by field emission scanning electron microscope (FE-SEM) and x-ray diffraction (XRD). The photocatalytic activity of $\mathrm{ZnO}$ nanoparticle was evaluated in a cylindrical glass reactor under VU-C irradiation light. Central composite design (CCD) and response surface methodology (RSM) were employed for modeling and optimizing the IBP degradation under different variables such as initial $\mathrm{pH}, \mathrm{ZnO}$ loading, humic acid concentration, initial IBP concentration, and reaction time. The results of our experiments showed that the reaction time had its highest positive effect on IBP degradation. The correlation coefficient $\left(\mathrm{R}^{2}\right)$ value of 0.856 indicated a good agreement between the experimental results and the model predictions. Optimization results showed that the maximum IBP degradation was attained at optimum conditions of $\mathrm{pH}$ 6.7, catalyst loading $583 \mathrm{mg} / \mathrm{L}$, initial IBP concentration $1.5 \mathrm{mg} / \mathrm{L}$, humic acid concentration $54 \mathrm{mg} / \mathrm{L}$, and reaction time of $95 \mathrm{~min}$. Under these conditions we achieved maximum IBP removal efficiency of $82.97 \%$. In conclusion, $\mathrm{ZnO}$ was found to be an effective photo catalyst and a promising alternative for producing free $\mathrm{OH}$ radicals for degradation of ibuprofen as an emerging pollutant in water resources.
\end{abstract}

Keywords: photocatalysis, $\mathrm{ZnO}$ nanoparticles, Ibuprofen, response surface methodology

*e-mail: anvarasadi@sbmu.ac.ir 


\section{Introduction}

The widespread use of hazardous pharmaceuticals has led to increasing pollution of surface, ground, and drinking water by these substances at low concentrations. Among pharmaceuticals, steroids, nonprescription drugs, and antibiotics occur at higher concentrations in aqueous environments [1]. Non-steroidal anti-inflammatory drugs (NSAIDs) such as ibuprofen, naproxen, diclofenac, and ketoprofen are the most frequently detected medicines, and their environmental distribution is widespread [2]. Based on selected characteristic properties, these drugs have the ability to be persistent during conventional treatment and release to the environment [2].

Most recently, several physical and chemical remediation technologies such as advanced oxidation processes (AOPs), filtration, adsorption, coagulationflocculation, and flotation have been reported for the removal of NSAIDs from water and wastewaters [35]. AOPs as an environmentally friendly and green technology produce a very powerful oxidizing agent, hydroxyl radical ${ }^{\bullet} \mathrm{OH}$, which appears to be an alternative for the degradation of NSAIDs - especially at low concentrations [6]. One of the AOPs is the heterogeneous photocatalysis process, which use semiconductors such as $\mathrm{ZnO}, \mathrm{CdS}$, and $\mathrm{TiO}_{2}$ under UV/visible light as a powerful technique for removing recalcitrant organic pollutants [7-8]. The $\mathrm{ZnO}$ semiconductor is comprised of a valence band and conductance band which under illumination higher than band gap produces electron-hole pairs $\left(\mathrm{h}^{+} / \mathrm{e}^{-}\right)$ and is transferred to the $\mathrm{ZnO}$ surface, where they are then available to undergo redox reactions with substrates [9]. The following series of elementary reaction steps (Eqs. 1-8) are a simplified for reactions involving $\mathrm{ZnO}$ [10]:

$$
\begin{gathered}
\mathrm{ZnO}+\mathrm{hv} \longrightarrow \mathrm{h}^{+}+e^{-} \\
e^{-}+\mathrm{O}_{2} \rightarrow \mathrm{O}_{2}^{\bullet-} \\
\mathrm{O}_{2}^{\bullet-}+\mathrm{H}_{2} \mathrm{O}_{2} \rightarrow \mathrm{H}^{+} \rightarrow \mathrm{H}_{2} \mathrm{O}_{2} \\
e^{-}+\mathrm{H}_{2} \mathrm{O}_{2} \rightarrow \mathrm{OH}^{-}+\mathrm{OH}_{2} \\
h^{+}+\mathrm{OH}^{-} \rightarrow{ }^{\bullet} \mathrm{OH}^{-} \\
h^{+}+\mathrm{H}_{2} \mathrm{O} \rightarrow \mathrm{H}^{+}+{ }^{\bullet} \mathrm{OH}^{\circ} \\
2 h^{+}+2 \mathrm{H}_{2} \mathrm{O} \rightarrow 2 \mathrm{H}^{+}+\mathrm{H}_{2} \mathrm{O}_{2}
\end{gathered}
$$

Therefore, in heterogeneous photocatalysis several oxidative agents could be produced: the photogenerated holes $\mathrm{h}^{+}, \bullet \mathrm{OH}$ radicals, $\mathrm{O}^{\bullet}{ }_{2}$ radicals, and $\mathrm{H}_{2} \mathrm{O}_{2}-$ which are known as strongly active and degrading agents [11].
The aim of the present study was to evaluate the potential of a UV/ZnO process for treatment of waters contaminated by IBP, using RSM with considering operational parameters such as initial $\mathrm{pH}$, catalyst loading, initial IBP concentration, humic acid concentration, and reaction time. The central composite design (CCD) has been used for optimizing and modeling ibuprofen removal from the aqueous matrix.

\section{Materials and Methods}

\section{Material}

Ibuprofen ( $>98 \%$ purity) was obtained from Hakim Pharmaceutical co., Tehran, Iran. Commercial standard zinc oxide powder (GR) was purchased from Nano Pars Spadana, Isfahan, Iran, and its chemical structure and other characteristics are presented in our previous work [12]. $\mathrm{X}$-ray diffraction patterns of the catalyst were carried out at room temperature with a STOE (Darmstadt, Germany) diffractometer using $\mathrm{Cu} \mathrm{K \alpha}$ radiation $(\lambda=1.54060 \AA \hat{)})$. Field emission scanning electron microscopy (FE-SEM, Hitachi S-4160, Japan) was used for the morphological characterization of the catalyst. Humic acid was obtained from Sigma-Aldrich Co., USA, and used without further purification.

\section{Experimental Set-Up and Procedure}

An aqueous solution of IBP was prepared by adding the appropriate amount of IBP to methanol and yielding $1000 \mathrm{mg} / \mathrm{L}$ stock solution. The desired IBP concentrations $(1.5-13 \mathrm{mg} / \mathrm{L})$ were prepared from stock by dilution in deionized water. To detect and quantify IBP, the range of concentrations in this study is higher than those typically detected in the water resources [11]. Photocatalytic experiments were carried out in a cylindrical glass reactor with workable area of $0.07 \times 0.25 \mathrm{~m}$, fitted in a cooling bath. A $125 \mathrm{~W}$ medium pressure Hg vapor lamp (UV-C) with peak intensity at $254 \mathrm{~nm}$ was positioned above the reactor. The total suspension volume was $250 \mathrm{ml}$. Prior to each run, the substrate was maintained stirringly in the dark for $20 \mathrm{~min}$ to ensure adsorption-desorption equilibrium. The suspension $\mathrm{pH}$ values were adjusted by $0.1 \mathrm{M} \mathrm{NaOH}$ and $\mathrm{HCl}$. At a given time interval, $2 \mathrm{~mL}$ aliquots of the aqueous suspension was withdrawn and filtered through syringe filters $(\varnothing=0.22 \mu \mathrm{m})$ to remove the remaining $\mathrm{ZnO}$ nanoparticles. The concentration of IBP in the filtered sample was determined by HPLC (Knauer, Germany) at a wavelength of $230 \mathrm{~nm}$. The mobile phase consisted of $70 \%$ acetonitrile (HPLC Grade, Merck) and 30\% ultrapure water controlled at $\mathrm{pH} 3$ by phosphoric acid. The flow rate was $1.2 \mathrm{~mL} / \mathrm{min}$ and the sample volume was $20 \mu \mathrm{L}$.

\section{Experimental Design Based on CCD}

RSM based on central composite design (CCD) as a widely used experimental design was used to optimize 
Table 1. Predictor variables and their coded levels and actual values used for experimental design.

\begin{tabular}{|c|c|c|c|c|c|}
\hline \multirow{2}{*}{ Variable } & \multicolumn{5}{|c|}{ Real values of coded levels } \\
\cline { 2 - 6 } & $-\alpha$ & -1 & 0 & 1 & $+\alpha$ \\
\hline $\mathrm{pH}\left(\mathrm{x}_{1}\right)$ & 2 & 5 & 8 & 10 & 13 \\
\hline Catalyst loading $\left(\mathrm{x}_{2}\right)$ & 93 & 300 & 450 & 600 & 807 \\
\hline IBP concentration $\left(\mathrm{x}_{3}\right)$ & 1.5 & 5 & 7.5 & 10 & 13 \\
\hline Humic acid $\left(\mathrm{x}_{4}\right)$ & 16 & 50 & 75 & 100 & 134 \\
\hline Time $\left(\mathrm{x}_{5}\right)$ & 10 & 12 & 45 & 70 & 95 \\
\hline
\end{tabular}

IBP degradation by photocatalysis. Design-Expert and Minitab 17 software were used to analyze the obtained experimental data. The effect of five independent variables (factors) influencing the photocatalytic IBP degradation was evaluated: $\mathrm{pH}$, catalyst loading (mg/L), the initial IBP concentration $(\mathrm{mg} / \mathrm{L})$, humic acid concentration $(\mathrm{mg} / \mathrm{L})$, and reaction time (min). Each factor in the design was studied at three different levels (low (-1), average (0), high (1)). The ranges and the levels of these factors assessed in this study are presented in Table 1.

The experimental response (Y) was related to selected factors with full quadratic model in terms of coded variables as follows:

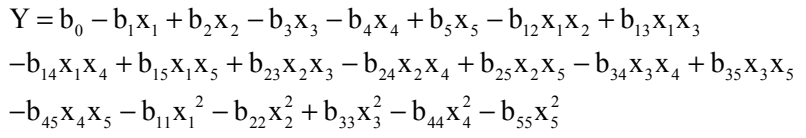

...where $Y$ is a response variable of IBP degradation efficiency, $b_{0}$ is an intercept, $b_{i}$ the regression coefficients for linear effects, $b_{i i}$ the regression coefficients for quadratic effects, $b_{i j}$ the regression coefficients for interaction effects, and $X_{i}$ are coded experimental levels of the variables. The quality of fitting the quadratic model was expressed by the coefficient of determination $\mathrm{R}^{2}$. Data from the study were analyzed by the analysis of variance (ANOVA).

\section{Results}

\section{General ZnO Characterization}

The $\mathrm{ZnO}$ catalyst used in the present work was a yellowish-white color with a specific surface area of about $50 \mathrm{~m}^{2} / \mathrm{g}$ and $99.8 \%$ purity. The catalyst was activated at $200^{\circ} \mathrm{C}$ for two hours. Fig. 1a illustrates the XRD pattern of pure $\mathrm{ZnO}$ nanoparticle. The catalyst has a wurtzite structure and their XRD peaks were in good agreement with the standard card for the hexagonal $\mathrm{ZnO}$ crystal (JCPDS 36-1451). The average dimension (D) of particles was calculated using Debye-Sherrer's formula [8] and found to be $28 \mathrm{~nm}$. The morphologies of the catalyst were
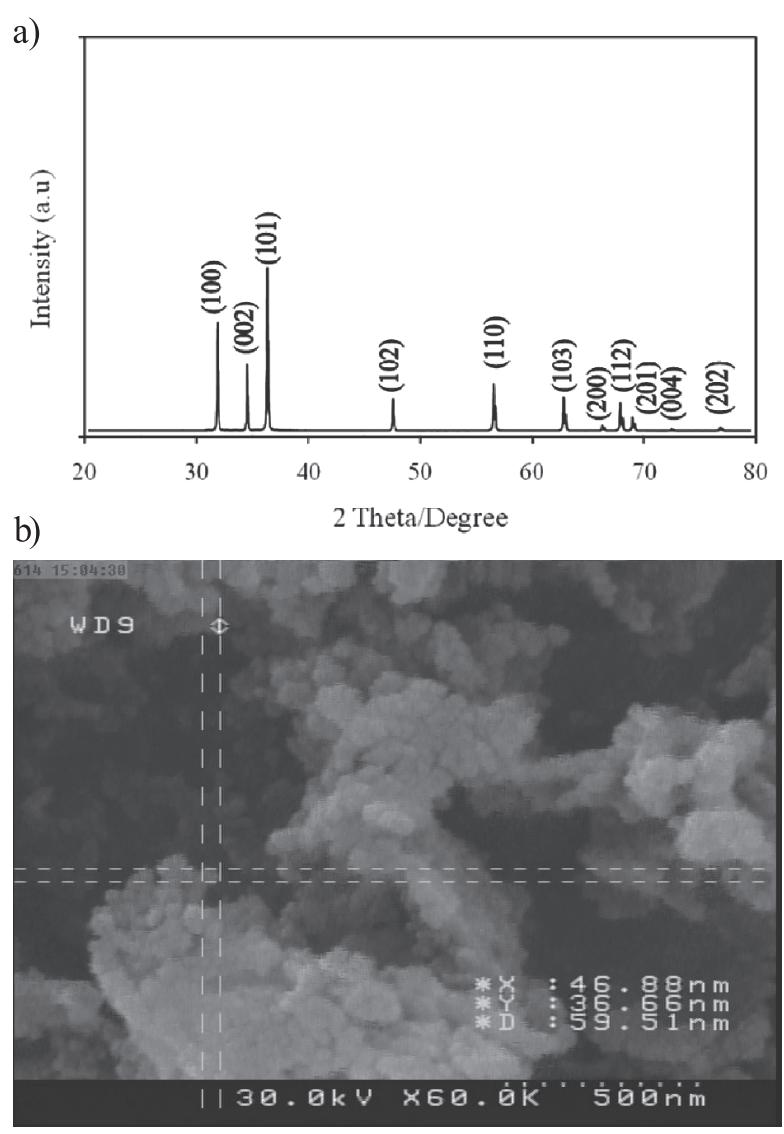

c)

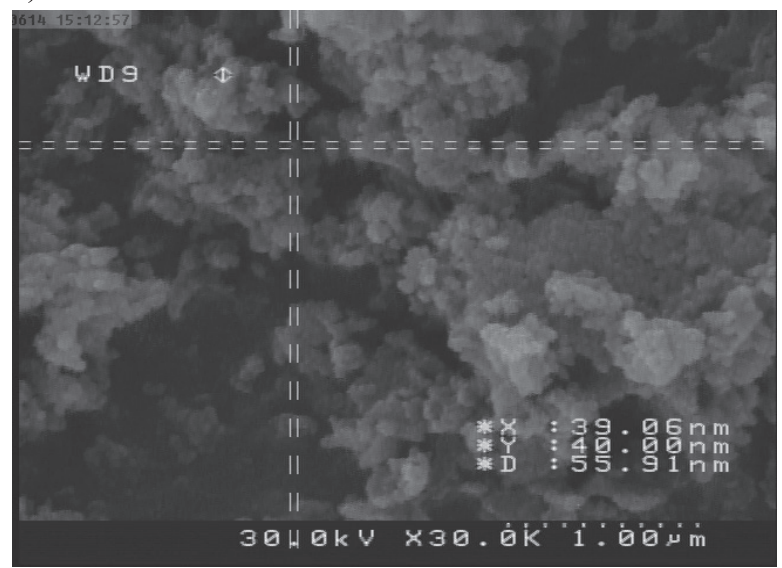

d)

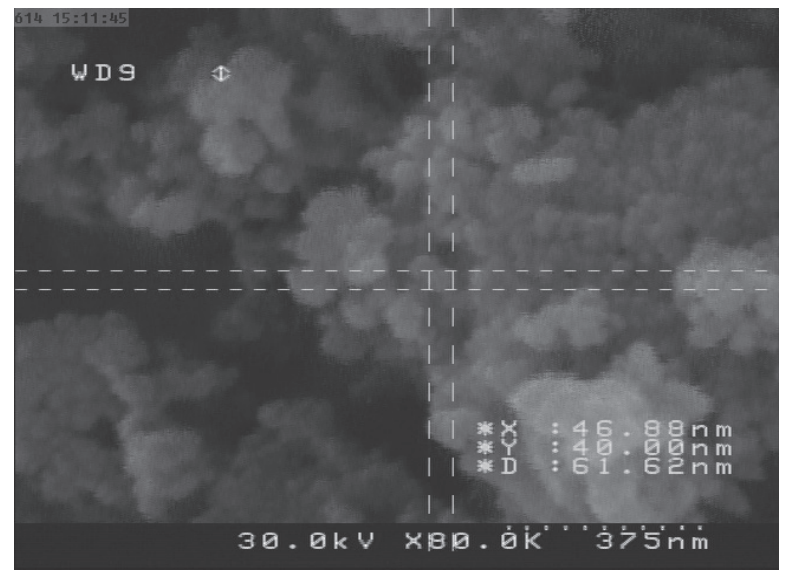

Fig. 1. a) XRD pattern of $\mathrm{ZnO}$, and b), c), and d) FESEM images of $\mathrm{ZnO}$ at different magnifications. 


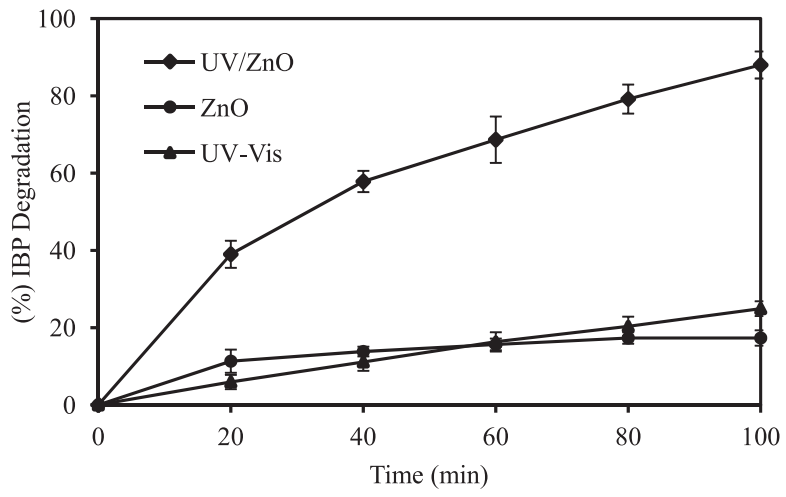

Fig. 2. Photocatalytic degradation of IBP over $\mathrm{ZnO}$ under different conditions: $\mathrm{pH} 7$, catalyst load $500 \mathrm{mg} / \mathrm{L}$, IPB concentration $5 \mathrm{mg} / \mathrm{L}$, and Humic acid concentration $50 \mathrm{mg} / \mathrm{L}$.

characterized by FE-SEM shown in Fig. 1 (b, c, and d). The approximate spherical shape of $\mathrm{ZnO}$ nanoparticles are observed in the figures. We can see that the size of the nanoparticles is between $25-35 \mathrm{~nm}$, which is in agreement with particle diameters estimated by Debye-Sherrer's equation.

\section{Preliminary Studies}

Preliminary studies were performed to evaluate the effect of adsorption (pure $\mathrm{ZnO}$ ), photolysis (UV irradiation alone), and photocatalyst (UV/ZnO) on IBP removal efficiency. The degradation curves of IBP as a function of reaction time are plotted in Fig. 2. From Fig. 2 it can be seen that adsorption and photolysis were contributed for 18 and $25 \%$ IBP removal, respectively, within $100 \mathrm{~min}$ of reaction time. Each factor alone could not have significant removal efficiency in this reaction time. On the other hand, the synergistic effect between the $\mathrm{ZnO}$ and UV light could effectively remove the IBP by photocatalysis $(98 \%$ removal in $100 \mathrm{~min}$ reaction time). The results of these experiments are higher than a previous study by Choina et al. [13], which reached $60 \%$ abatement of ibuprofen at $5 \mathrm{mg} / \mathrm{L}$ of IBP concentration. The finding is also in agreement with another study [11] on the photocatalytic ( $\mathrm{ZnO} / \mathrm{UV})$ oxidation of ibuprofen, which obtained ca. $80 \%$ degradation in $10 \mathrm{mg} / \mathrm{L} \mathrm{IBP}$ and catalyst loading of $50 \mathrm{mg} / \mathrm{L}$.

\section{Response Surface Methodology \\ Model Fitting and Statistical Analysis}

To optimize IBP degradation, central composite design (CCD) with a total number of 50 runs was used for response surface modeling. The five-parameter CCD matrix and experimental results obtained in the photocatalytic IBP degradation runs are presented in Table 2. Design Expert software was used to obtain the best fitted model. As presented in Table 3, the quadratic model was suggested by the software and it was supported with lack of fit and model summary statistics.

Table 4 shows the results of the quadratic response surface model fitting in the form of analysis of variance (ANOVA).

Based on these results, RSM offers an empirical relationship between IBP degradation and independent variables as in the following quadratic model:

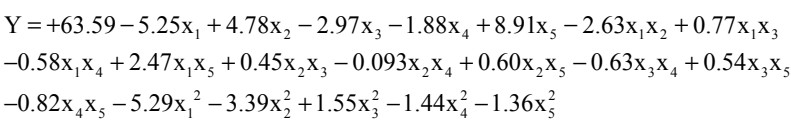

...where $\mathrm{Y}$ is the percentage degradation of IBP (\%); and $\mathrm{x}_{1}, \mathrm{x}_{2}, \mathrm{x}_{3}, \mathrm{x}_{4}$, and $\mathrm{x}_{5}$ are terms for the coded values of $\mathrm{pH}$, catalyst loading $(\mathrm{mg} / \mathrm{L})$, IBP concentration $(\mathrm{mg} / \mathrm{L})$, humic acid concentration $(\mathrm{mg} / \mathrm{L})$, and time $(\mathrm{min})$, respectively.

Table 5 shows the Student's $t$ distribution and the corresponding values, along with the parameter estimate.

Table 2. Five-factor central composite design matrix along with the observed responses.

\begin{tabular}{|c|c|c|c|c|c|c|c|}
\hline \multirow{2}{*}{ Run } & \multirow{2}{*}{$\mathrm{pH}$} & Cat. loading $(\mathrm{mg} / \mathrm{L})$ & IBP Con. $(\mathrm{mg} / \mathrm{L})$ & $\begin{array}{c}\text { Humic acid con. } \\
(\mathrm{mg} / \mathrm{L})\end{array}$ & $\begin{array}{c}\text { Time } \\
(\mathrm{min})\end{array}$ & \multicolumn{2}{|c|}{ \% IBP degradation } \\
\hline 1 & 8 & 450 & 7.5 & 75 & 10 & 31 & 37.2 \\
\hline 2 & 10 & 600 & 5 & 50 & 45 & 44 & 58.5 \\
\hline 3 & 8 & 450 & 7.5 & 134 & 70 & 53 & 53.5 \\
\hline 4 & 10 & 300 & 5 & 100 & 45 & 38 & 42.4 \\
\hline 5 & 8 & 450 & 7.5 & 75 & 12 & 32.5 & 37.9 \\
\hline 6 & 10 & 600 & 5 & 100 & 45 & 51 & 52.9 \\
\hline 7 & 5 & 300 & 10 & 50 & 95 & 58 & 67.4 \\
\hline 8 & 5 & 600 & 10 & 50 & 95 & 78 & 78.0 \\
\hline 9 & 13 & 450 & 7.5 & 75 & 70 & 42 & 53.5 \\
\hline
\end{tabular}


Table 2. Continued.

\begin{tabular}{|c|c|c|c|c|c|c|c|}
\hline 10 & 5 & 300 & 5 & 100 & 45 & 61 & 48.0 \\
\hline 11 & 10 & 300 & 10 & 100 & 95 & 56 & 56.2 \\
\hline 12 & 5 & 300 & 5 & 50 & 45 & 55 & 53.6 \\
\hline 13 & 10 & 600 & 5 & 100 & 95 & 66 & 72.0 \\
\hline 14 & 10 & 300 & 5 & 50 & 45 & 49 & 47.9 \\
\hline 15 & 10 & 600 & 5 & 50 & 95 & 71 & 77.6 \\
\hline 16 & 8 & 450 & 7.5 & 75 & 70 & 59 & 60.2 \\
\hline 17 & 5 & 300 & 5 & 50 & 95 & 65 & 72.7 \\
\hline 18 & 10 & 300 & 5 & 100 & 95 & 64 & 61.5 \\
\hline 19 & 10 & 600 & 10 & 50 & 95 & 73 & 72.4 \\
\hline 20 & 8 & 450 & 7.5 & 75 & 70 & 58 & 60.2 \\
\hline 21 & 8 & 807 & 7.5 & 75 & 70 & 70 & 72.7 \\
\hline 22 & 10 & 300 & 10 & 50 & 95 & 70 & 61.8 \\
\hline 23 & 10 & 300 & 10 & 50 & 45 & 40 & 42.7 \\
\hline 24 & 8 & 450 & 7.5 & 75 & 70 & 60 & 60.2 \\
\hline 25 & 8 & 450 & 7.5 & 16 & 70 & 69 & 66.8 \\
\hline 26 & 5 & 600 & 10 & 50 & 45 & 64 & 58.8 \\
\hline 27 & 8 & 450 & 7.5 & 75 & 70 & 60 & 60.2 \\
\hline 28 & 2 & 450 & 7.5 & 75 & 70 & 38 & 66.8 \\
\hline 29 & 5 & 600 & 5 & 50 & 45 & 70 & 64.1 \\
\hline 30 & 10 & 600 & 10 & 100 & 45 & 34 & 47.6 \\
\hline 31 & 5 & 300 & 5 & 100 & 95 & 60 & 67.1 \\
\hline 32 & 8 & 450 & 7.5 & 75 & 70 & 77 & 60.2 \\
\hline 33 & 10 & 300 & 10 & 100 & 45 & 40 & 37.1 \\
\hline 34 & 10 & 600 & 10 & 50 & 45 & 44 & 53.2 \\
\hline 35 & 8 & 450 & 1.5 & 75 & 70 & 79 & 66.5 \\
\hline 36 & 5 & 300 & 10 & 100 & 95 & 55 & 61.9 \\
\hline 37 & 8 & 93 & 7.5 & 75 & 70 & 30 & 47.6 \\
\hline 38 & 10 & 600 & 10 & 100 & 95 & 65 & 66.8 \\
\hline 39 & 5 & 600 & 5 & 100 & 45 & 64 & 58.5 \\
\hline 40 & 8 & 450 & 7.5 & 75 & 70 & 81 & 60.2 \\
\hline 41 & 10 & 300 & 5 & 50 & 95 & 74 & 67.1 \\
\hline 42 & 5 & 300 & 10 & 100 & 45 & 45 & 42.7 \\
\hline 43 & 5 & 600 & 10 & 100 & 95 & 70 & 72.4 \\
\hline 44 & 5 & 600 & 10 & 100 & 45 & 58 & 53.2 \\
\hline 45 & 8 & 450 & 7.5 & 75 & 70 & 80 & 60.2 \\
\hline 46 & 5 & 600 & 5 & 100 & 95 & 76 & 77.7 \\
\hline 47 & 8 & 450 & 7.5 & 75 & 70 & 83 & 60.2 \\
\hline 48 & 5 & 300 & 10 & 50 & 45 & 48 & 48.3 \\
\hline 49 & 5 & 600 & 5 & 50 & 95 & 83 & 83.2 \\
\hline 50 & 8 & 450 & 13 & 75 & 70 & 78 & 54.4 \\
\hline
\end{tabular}


Table 3. Sequential model fitting for IBP degradation.

\begin{tabular}{|c|c|c|c|c|c|c|}
\hline \multicolumn{7}{|c|}{ Sequential Model Sum of Squares } \\
\hline Source & $\begin{array}{l}\text { Sum of } \\
\text { Squares }\end{array}$ & $\mathrm{df}$ & Mean Square & F Value & $\begin{array}{c}\text { p-value Prob } \\
>\mathrm{F}\end{array}$ & \\
\hline Mean & $176,358.6$ & 1 & $176,358.6$ & & & \\
\hline Linear & $5,964.7$ & 5 & $1,192.9$ & 10.4 & $<0.0001$ & \\
\hline $2 \mathrm{FI}$ & 880.5 & 10 & 88.1 & 0.7 & 0.7015 & \\
\hline Quadratic & $2,577.2$ & 5 & 515.4 & 9.4 & $<0.0001$ & Suggested \\
\hline Cubic & 552.6 & 16 & 34.5 & 0.4 & 0.9427 & Aliased \\
\hline Residual & $1,037.7$ & 13 & 79.8 & & & \\
\hline Total & $187,371.3$ & 50 & $3,747.4$ & & & \\
\hline \multicolumn{7}{|c|}{ Lack of Fit Tests } \\
\hline Source & $\begin{array}{l}\text { Sum of } \\
\text { Squares }\end{array}$ & df & Mean Square & F Value & $\begin{array}{c}\text { p-value Prob } \\
>\text { F }\end{array}$ & \\
\hline Linear & $4,144.4$ & 37 & 112.0 & 0.9 & 0.6469 & \\
\hline $2 \mathrm{FI}$ & $3,263.9$ & 27 & 120.9 & 0.9 & 0.5897 & \\
\hline Quadratic & 686.7 & 22 & 31.2 & 0.2 & 0.9952 & Suggested \\
\hline Cubic & 134.2 & 6 & 22.4 & 0.2 & 0.9758 & Aliased \\
\hline Pure Error & 903.5 & 7 & 129.1 & & & \\
\hline \multicolumn{7}{|c|}{ Model Summary Statistics } \\
\hline Source & Std. Dev. & $\mathrm{R}^{2}$ & Adjusted $\mathrm{R}^{2}$ & Predicted $\mathrm{R}^{2}$ & PRESS & \\
\hline Linear & 10.7 & 0.542 & 0.490 & 0.428 & 6298 & \\
\hline $2 \mathrm{FI}$ & 11.1 & 0.622 & 0.455 & 0.458 & 5973 & \\
\hline Quadratic & 7.4 & 0.856 & 0.756 & 0.630 & 4071 & Suggested \\
\hline Cubic & 8.9 & 0.906 & 0.645 & & + & Aliased \\
\hline
\end{tabular}

\section{Graphical Presentation of the Model and Optimization}

The study of the response surface and contour graphs provides a prediction of IBP removal efficiency and identifies the type of interactions between variables [14-16]. Figs. 3-6 show the response surface plots and contours for the optimization of IBP degradation. Indeed, the results of the interactions between the four independent variables and the dependent variable are shown in Figs 3-6. In each plot, two variables are varied while the others are maintained at their respective zero level. Fig. 3 shows the simultaneous effect of $\mathrm{pH}$ and catalyst loading. The degree of degradation increased with increasing catalyst load up to $\sim 500 \mathrm{mg} / \mathrm{L}$ and then decreased.

Table 4. Analysis of variance (ANOVA) for the selected quadratic model.

\begin{tabular}{|c|c|c|c|c|c|c|}
\hline Source & Sum of Squares & df & Mean Square & F Value & p-value Prob $>$ F & \\
\hline Model & $9,422.4$ & 20 & 471.1 & 8.6 & $<0.0001$ & significant \\
\hline Residual & $1,590.2$ & 29 & 54.8 & & & \\
\hline Lack of Fit & 686.7 & 22 & 31.2 & 0.2 & 0.9952 & not significant \\
\hline Pure Error & 903.5 & 7 & 129.1 & & & \\
\hline Cor Total & $11,012.6$ & 49 & & & & \\
\hline
\end{tabular}


Table 5. Regression results from the data of central composite design experiments.

\begin{tabular}{|c|c|c|c|c|c|}
\hline Term & Effect & $\begin{array}{c}\text { Coefficient } \\
\text { Estimate }\end{array}$ & $\begin{array}{c}\text { SE } \\
\text { Coef. }\end{array}$ & T-Value & P-Value \\
\hline Constant & & 62.78 & 2.46 & 25.56 & 0.000 \\
\hline $\mathrm{X}_{1}$ & -25.1 & -12.55 & 3.41 & -3.68 & 0.001 \\
\hline $\mathrm{X}_{2}$ & 22.3 & 11.16 & 3.4 & 3.28 & 0.003 \\
\hline $\mathrm{X}_{3}$ & -15.1 & -7.58 & 3.31 & -2.29 & 0.029 \\
\hline $\mathrm{X}_{4}$ & -9.0 & -4.52 & 3.4 & -1.33 & 0.194 \\
\hline $\mathrm{X}_{5}$ & 43.3 & 21.69 & 2.57 & 8.43 & 0.000 \\
\hline $\mathrm{X}_{1}^{2}$ & -57.5 & -28.76 & 5.53 & -5.2 & 0.000 \\
\hline $\mathrm{X}_{2}^{2}$ & -37.4 & -18.72 & 5.52 & -3.39 & 0.002 \\
\hline $\mathrm{X}_{3}^{2}$ & 12.7 & 6.36 & 5.46 & 1.16 & 0.254 \\
\hline $\mathrm{X}_{4}^{2}$ & -15.4 & -7.72 & 5.52 & -1.4 & 0.173 \\
\hline $\mathrm{X}_{5}^{2}$ & -16.5 & -8.26 & 3.16 & -2.62 & 0.014 \\
\hline $\mathrm{X}_{1} \times \mathrm{X}_{2}$ & -35.0 & -17.51 & 7.28 & -2.41 & 0.023 \\
\hline $\mathrm{X}_{1} \times \mathrm{X}_{3}$ & 7.8 & 3.93 & 7.04 & 0.56 & 0.581 \\
\hline $\mathrm{X}_{1} \times \mathrm{X}_{4}$ & -6.7 & -3.36 & 7.28 & -0.46 & 0.648 \\
\hline $\mathrm{X}_{1} \times \mathrm{X}_{5}$ & 30.9 & 15.05 & 5.2 & 2.89 & 0.007 \\
\hline $\mathrm{X}_{2} \times \mathrm{X}_{3}$ & 5.1 & 2.56 & 7.03 & 0.36 & 0.718 \\
\hline $\mathrm{X}_{2} \times \mathrm{X}_{4}$ & -1.0 & -0.53 & 7.27 & -0.07 & 0.942 \\
\hline $\mathrm{X}_{2} \times \mathrm{X}_{5}$ & 6.8 & 3.41 & 5.2 & 0.66 & 0.517 \\
\hline $\mathrm{X}_{3} \times \mathrm{X}_{4}$ & -7.18 & -3.59 & 7.03 & -0.51 & 0.614 \\
\hline $\mathrm{X}_{3} \times \mathrm{X}_{5}$ & 6.11 & 3.05 & 5.03 & 0.61 & 0.548 \\
\hline $\mathrm{X}_{4} \times \mathrm{X}_{5}$ & -9.35 & -4.67 & 5.2 & -0.9 & 0.376 \\
\hline
\end{tabular}

Fig. 4. Shows the simultaneous effect of IBP concentration and catalyst loading.

Figs 5 and 6 show the simultaneous effects of IBP vs. humic acid concentration and time vs. humic acid, respectively. As can be seen from Fig. 6, the degradation of IBP increased with increasing reaction time.

To optimize the operational parameters for maximum degradation efficiency, the operational factors were set to values within the studied range, whereas the response (IBP degradation efficiency) was set to achieve a maximum value. Based on this approach, maximum degradation efficiency was $90.4 \%$ at an initial $\mathrm{pH}$ of 6.7 , catalyst loading of $583 \mathrm{mg} / \mathrm{L}$, initial IBP concentration of $1.5 \mathrm{mg} / \mathrm{L}$, initial humic acid concentration of $54 \mathrm{mg} / \mathrm{L}$, and reaction time of $95 \mathrm{~min}$. For validation study of optimal variables, additional experiments were carried out to confirm degradation efficiency. The result of optimization performed by Minitab 16 software showed that under optimal conditions the maximum degradation of $82.97 \%$ was obtained experimentally. This indicated the suitability and accuracy of the model.
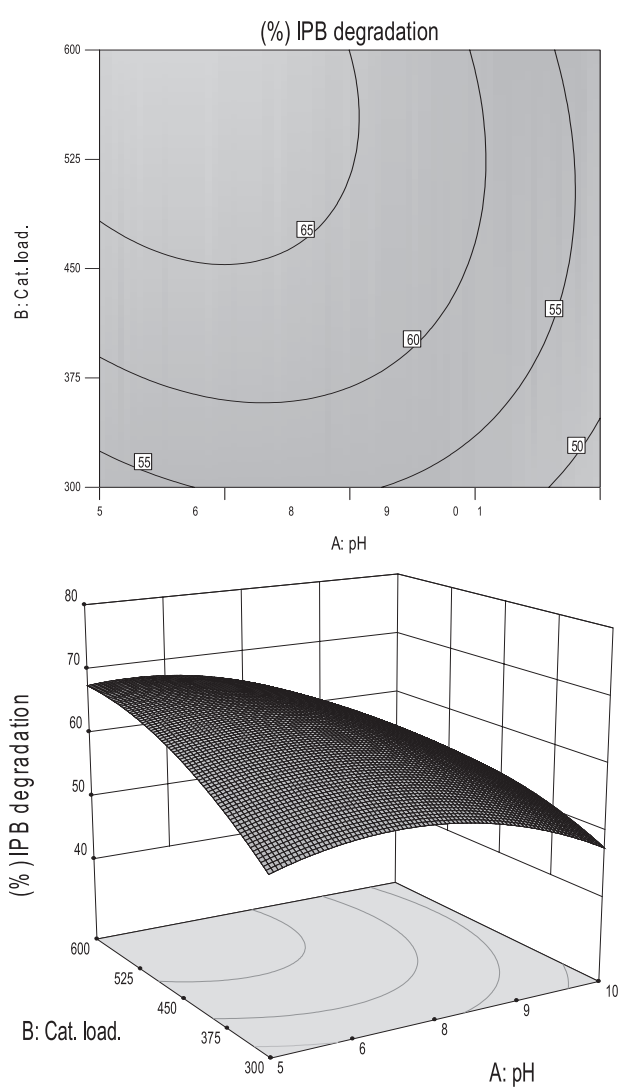

Fig. 3. The counter plot and corresponding response surface plot of IBP degradation as a function of $\mathrm{pH}$ and catalyst loading $(\mathrm{mg} / \mathrm{L})$.
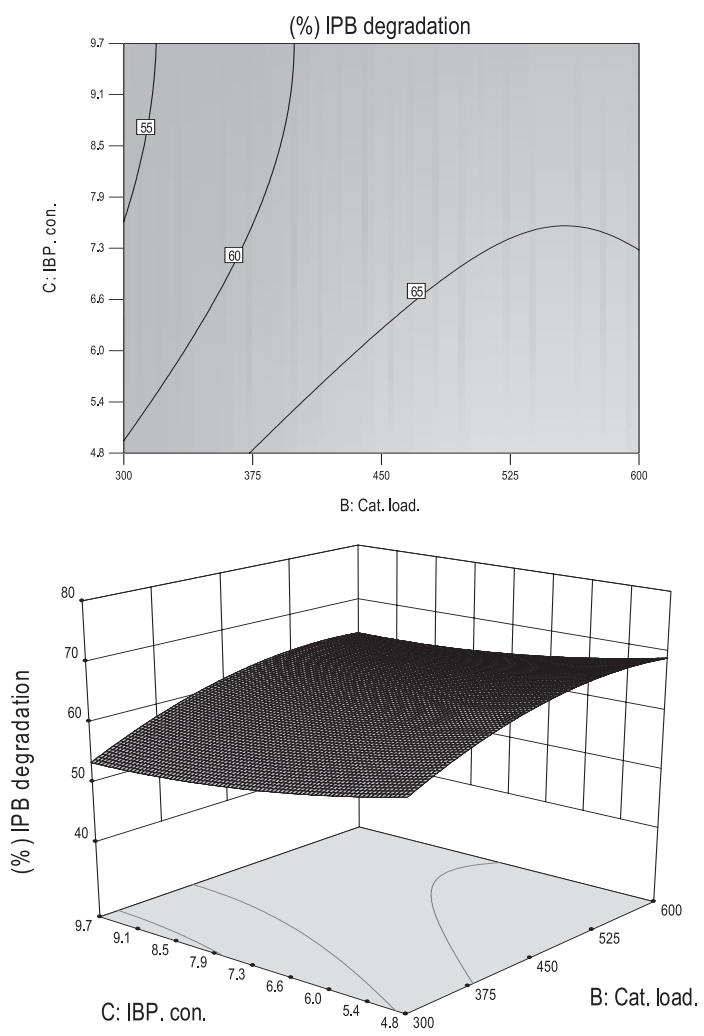

Fig. 4. The counter plot and corresponding response surface plot of IBP degradation as a function of catalyst loading $(\mathrm{mg} / \mathrm{L})$ and initial IBP concentration $(\mathrm{mg} / \mathrm{L})$. 

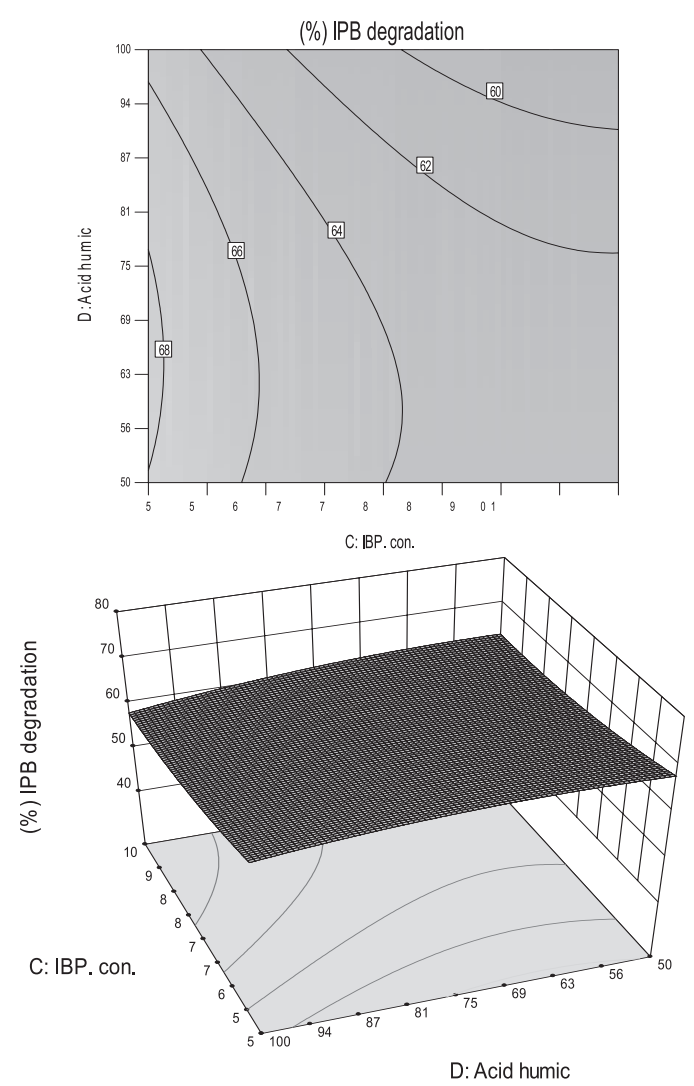

Fig. 5. The counter plot and corresponding response surface plot of IBP degradation as a function of initial IBP concentration $(\mathrm{mg} / \mathrm{L})$ and humic acid concentration $(\mathrm{mg} / \mathrm{L})$.
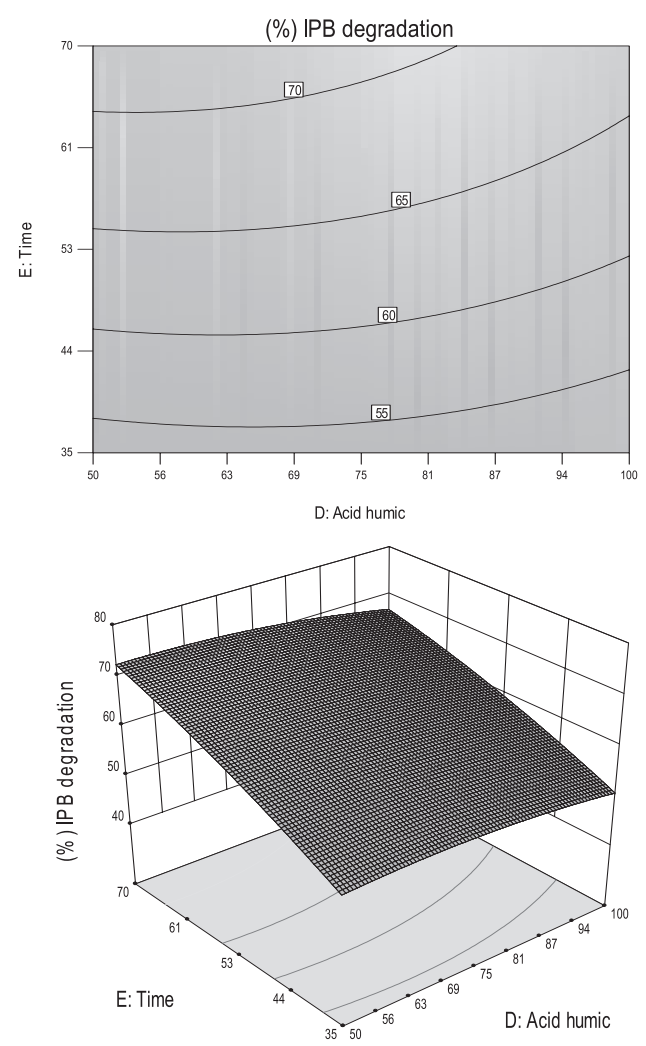

Fig. 6. The counter plot and corresponding response surface plot of IBP degradation as a function of time (min) and humic acid concentration $(\mathrm{mg} / \mathrm{L})$.

\section{Discussion}

The ANOVA of the quadratic regression model indicates that the model is highly significant, as is evident from the Fisher F-test $(\mathrm{F}$ model $=8.59)$ and a very low p-value prob $>\mathrm{F}(<0.0001)$. The probability $\mathrm{P}$-value is relatively low, indicating the significance of the model. The tabular F-value $\left(\mathrm{F}_{0.05,5,44}=2.43\right)$ is much lower than the computed F-value (8.59) at the $1 \%$ level, which indicates the great significance of IBP degradation. The lack of fit of the model occurs when the model does not adequately represent the mean response as a function of the factor levels. Here, the lack of fit value is 0.241 , which indicates that the lack of fit is not significant relative to the pure error when $p=0.995$, which is $>0.05$. The insignificant lack of fit indicates good predictability. The model fitting could be also checked by the coefficient of determination, which lies between 0 and 1 . The value of $\mathrm{R}^{2}$ is 0.855 , which indicates that $85.5 \%$ of the variability in the response could be explained by quadratic model. To correct the number of factors in the model and sample size, the adjusted $\mathrm{R}^{2}$ could be used. However, adding a variable to the model could always increase $\mathrm{R}^{2}$, regardless of whether or not the additional variables are statistically significant [14]. Thus, some researchers prefer to use adjusted $\mathrm{R}^{2}$. When variables are added to the model, the adjusted $\mathrm{R}^{2}$ will not necessarily increase. In fact, if unnecessary variables are added to the model, the value of adjusted $\mathrm{R}^{2}$ is often decreasing. Large differences between $\mathrm{R}^{2}$ and adjusted $\mathrm{R}^{2}$ mean that insignificant variables are included in the model. Here, an adjusted $\mathrm{R}^{2}$ value 0.75 was relatively close to $\mathrm{R}^{2}$ value.

We used P-values o check the significance of each of the coefficients and as well as understand the pattern of the mutual interactions between the independent variables. The larger the magnitude of the t-value and smaller the $\mathrm{P}$-value, the more significant the corresponding coefficient [15]. As can be seen from Table 5, the linear effect of all terms (with the exception of humic acid concentration) is significant at 5\% significance level $(95 \%$ confidence interval). The quadratic relations between $\mathrm{pH}$, catalyst loading, and time were also significant. The mutual interaction effect of $\mathrm{pH}^{*}$ catalyst loading and $\mathrm{pH}^{*}$ time were significant, which indicated that these interactions improve IBP degradation efficiency. From the values of the coefficients in the regression model, the order in which independent variables effect the response is, time $\left(\mathrm{x}_{5}\right)>\mathrm{pH}\left(\mathrm{x}_{1}\right)>$ catalyst loading $\left(\mathrm{x}_{2}\right)>$ IBP concentration $\left(\mathrm{x}_{3}\right)>$ humic acid concentration $\left(\mathrm{x}_{4}\right)$. However, some terms such as $\mathrm{pH}$, IBP concentration, and humic acid concentration have a negative effect on response.

In Fig. 3, a preliminary increase in degradation with increasing catalyst load can be related to the increase in the amount of photon absorption on the catalyst surface, availability of active sites on $\mathrm{ZnO}$ surface, and light penetration of photo-activating light into the suspension, which promotes degradation efficiency. The decrease in degradation from a certain catalyst load may be due to increased opacity of the suspension and also increased 
light reflectance as a consequence of surplus $\mathrm{ZnO}$ particles [17]. The involved reactions in the $\mathrm{ZnO}$ photocatalyst system for removal of IBP as an organic pollutant are described before in equations 1 to 8 . However, when the $\mathrm{ZnO}$ semiconductor is illuminated with light energy greater than its band gap energy, excited high-energy states of electron $\left(\mathrm{e}^{-}\right)$and hole $\left(\mathrm{h}^{+}\right)$pairs are produced [18]. Electrons ( $\left.\mathrm{e}^{-}\right)$are trapped by surface $\mathrm{O}_{2}$ to produce the superoxide radicals $\left(\mathrm{O}_{2}^{\bullet-}\right)$, and also react with $\mathrm{O}_{2}^{\bullet}$ to produce $\mathrm{H}_{2} \mathrm{O}_{2}$. The superoxide radicals can combine with $\mathrm{H}_{2} \mathrm{O}_{2}$ to produce the ${ }^{\bullet} \mathrm{OH}$ radicals. Electrons (e-) can react with $\mathrm{H}_{2} \mathrm{O}_{2}$ and produce ${ }^{\bullet} \mathrm{OH}$ radicals. Holes $\left(\mathrm{h}^{+}\right)$are combined with ${ }^{-} \mathrm{OH}$ and $\mathrm{H}_{2} \mathrm{O}$ and produce ${ }^{\bullet} \mathrm{OH}$ radicals and $\mathrm{H}_{2} \mathrm{O}_{2}$. All of $\mathrm{h}^{+}, \mathrm{O}_{2}^{\bullet-}, \mathrm{H}_{2} \mathrm{O}_{2}$, and $\bullet \mathrm{OH}$ are reactive species responsible for the oxidizing ibuprofen [19]. $\mathrm{pH}$ has an important effect on the removal of IBP by the UV/ $\mathrm{ZnO}$ process. Apparently, the circumneutral condition is most favorable for IBP degradation by $\mathrm{ZnO}$. It has been reported that the $\mathrm{pH}$ of zero point charge for $\mathrm{ZnO}$ is 9.0 [20]. At $\mathrm{pH}$ value below the point of zero charge the catalyst surface becomes protonated and gets positive charge and at higher $\mathrm{pH}$ becomes deprotonated and get a negative charge. On the other hand, IBP is a weak acid that has a PKa value of 4.4. Therefore, the optimal degradation of IBP occurs at $\mathrm{PK}_{\mathrm{a}}^{\mathrm{IBP}}<\mathrm{pH}<\mathrm{pH}_{\mathrm{PZC}}^{\mathrm{ZnO}}$, of which $\mathrm{ZnO}$ has a positive charge and IBP molecule get a negative charge $[1,21]$.

Based on Fig. 4, the degradation of IBP decreases with increasing IBP concentration. As initial IBP concentration decreases, more hydroxyl radicals $\left({ }^{\bullet} \mathrm{OH}\right)$ are available to remove the IBP, which in turn leads to increasing IBP degradation efficiency [22].

To evaluate the effect of natural organic matter (NOM) on IBP degradation, humic acid was selected as a model of NOM since NOM is comprised of $\sim 70 \%$ humic acid [23]. As depicted in Fig. 5, the degradation of IBP diminishes with increasing humic acid concentration. However, as discussed earlier, at this level of humic acid concentration there is no significant effect on IBP degradation. Finally, Fig. 6 showed the effect of time and humic acid on IBP degradation. It can be seen that the large amount of IBP is degraded in the first $30 \mathrm{~min}$ of photocatalytic treatment. The rate of degradation decreased with increasing time above $30 \mathrm{~min}$, which related to a deactivation of the catalyst during the course of reaction. These results are in agreement with Sheikhnejad-Bishe et al. [24], which evaluated the effect of $\mathrm{TiO}_{2}$ nanoparticles synthesized via low temperature on the degradation of methyl orange under a $150 \mathrm{~W}$ xenon lamp.

\section{Conclusions}

The modeling and optimization of photocatalytic degradation of IBP in the $\mathrm{UVC} / \mathrm{ZnO}$ process was investigated using an RSM. The results showed that the optimum removal was occurring at the circumneutral $\mathrm{pH}$ condition. The amount of IBP degradation increased with initial concentration of the photocatalyst. A central composite design was used to develop a second-order polynomial model as a function of IBP removal and the five independent variables. The optimized factors for IBP removal determined in this work were set as follows: initial $\mathrm{pH}$ of 6.7 , catalyst loading of $583 \mathrm{mg} / \mathrm{L}$, initial IBP concentration of $1.5 \mathrm{mg} / \mathrm{L}$, initial humic acid concentration of $54 \mathrm{mg} / \mathrm{L}$, and reaction time of $95 \mathrm{~min}$. At this condition we obtained $82.97 \%$ removal of IBP.

\section{Acknowledgements}

This work was supported by grant No. 92-03-46-24061 from Tehran University of Medical Sciences, Institute for Environmental Research, Center for Water Quality Research (CWQR).

\section{References}

1. CHOINAJ., KOSSLICK H., FISCHER C., FLECHSIG G.U., FRUNZA L., SCHULZ A. Photocatalytic decomposition of pharmaceutical ibuprofen pollutions in water over titania catalyst. Applied Catalysis B: Environmental 129, 589, 2013.

2. ESLAMI A., AMINI M.M., YAZDANBAKHSH A.R., RASTKARI N., MOHSENI-BANDPEI A., NASSERI S., PIROTI E., ASADI A. Occurrence of non-steroidal antiinflammatory drugs in Tehran source water, municipal and hospital wastewaters, and their ecotoxicological risk assessment. Environmental monitoring and assessment 187, $1,2015$.

3. MÉNDEZ-ARRIAGA F., ESPLUGAS S., GIMÉNEZ J. Photocatalytic degradation of non-steroidal antiinflammatory drugs with $\mathrm{TiO}_{2}$ and simulated solar irradiation. Water Research 42, 585, 2008.

4. CARBALlA M., OMIL F., LEMA J.M. Removal of cosmetic ingredients and pharmaceuticals in sewage primary treatment. Water Research 39, 4790, 2005.

5. ZIYLAN A., INCE N.H. The occurrence and fate of antiinflammatory and analgesic pharmaceuticals in sewage and fresh water: Treatability by conventional and nonconventional processes. Journal of Hazardous Materials 187, 24, 2011.

6. BAUER R., WALDNER G., FALLMANN H., HAGER S., KLARE M., KRUTZLER T., MALATO S., MALETZKY P. The photo-Fenton reaction and the $\mathrm{TiO}_{2} / \mathrm{UV}$ process for waste water treatment- novel developments. Catalysis today $\mathbf{5 3}, 131,1999$.

7. CHONG M.N., JIN B. Photocatalytic treatment of high concentration carbamazepine in synthetic hospital wastewater. Journal of Hazardous Materials 199-200, 135, 2012.

8. SALARIAN A.-A., HAMI Z., MIRZAEI N., MOHSENI S.M., ASADI A., BAHRAMI H., VOSOUGHI M., ALINEJAD A., ZARE M.-R. N-doped $\mathrm{TiO}_{2}$ nanosheets for photocatalytic degradation and mineralization of diazinon under simulated solar irradiation: Optimization and modeling using a response surface methodology. Journal of Molecular Liquids 220, 183, 2016.

9. DAGHRIR R., DROGUI P., DIMBOUKOU-MPIRA A., EL KHAKANI M.A. Photoelectrocatalytic degradation of carbamazepine using $\mathrm{Ti} / \mathrm{TiO}_{2}$ nanostructured electrodes deposited by means of a pulsed laser deposition process. Chemosphere 93, 2756, 2013. 
10. CHO M., CHUNG H., CHOI W., YOON J. Different inactivation behaviors of MS-2 phage and Escherichia coli in $\mathrm{TiO}_{2}$ photocatalytic disinfection. Applied and environmental microbiology 71, 270, 2005.

11. GEORGAKI I., VASILAKI E., KATSARAKIS N. A Study on the Degradation of Carbamazepine and Ibuprofen by $\mathrm{TiO}_{2}$ \& ZnO Photocatalysis upon UV/Visible-Light Irradiation. 5, 518, 2014.

12. ASSADI A., DEHGHANI M.H., RASTKARI N., NASSERI S., MAHVI A.H. Photocatalytic reduction of hexavalent chromium in aqueous solutions with zinc oxide nanoparticles and hydrogen peroxide. Environment Protection Engineering 38, 5, 2012.

13. CHOINA J., BAGABAS A., FISCHER C., FLECHSIG G.U., KOSSLICK H., ALSHAMMARI A., SCHULZ A. The influence of the textural properties of $\mathrm{ZnO}$ nanoparticles on adsorption and photocatalytic remediation of water from pharmaceuticals. Catalysis Today 241, Part A, 47, 2015.

14. KUMAR J., BANSAL A. Photocatalytic degradation in annular reactor: Modelization and optimization using computational fluid dynamics (CFD) and response surface methodology (RSM). Journal of Environmental Chemical Engineering 1, 398, 2013.

15. LIU H.-L., CHIOU Y.-R. Optimal decolorization efficiency of Reactive Red 239 by $\mathrm{UV} / \mathrm{TiO}_{2}$ photocatalytic process coupled with response surface methodology. Chemical Engineering Journal 112, 173, 2005.

16. BOX G.E., DRAPER N.R. Empirical model-building and response surfaces, (Wiley New York, 1987).

17. KURIECHEN S.K., MURUGESAN S., RAJ S.P., MARUTHAMUTHU P. Visible light assisted photocatalytic mineralization of Reactive Red 180 using colloidal $\mathrm{TiO}_{2}$ and oxone. Chemical Engineering Journal 174, 530, 2011.
18. RADJENOVIĆ J., SIRTORI C., PETROVIĆ M., BARCELÓ D., MALATO S. Solar photocatalytic degradation of persistent pharmaceuticals at pilot-scale: Kinetics and characterization of major intermediate products. Applied Catalysis B: Environmental 89, 255, 2009.

19. ESLAMI A., AMINI M.M., YAZDANBAKHSH A.R., MOHSENI-BANDPEI A., SAFARI A.A., ASADI A. N,S codoped $\mathrm{TiO}_{2}$ nanoparticles and nanosheets in simulated solar light for photocatalytic degradation of non-steroidal antiinflammatory drugs in water: a comparative study. Journal of Chemical Technology \& Biotechnology, n/a, 2016.

20. PARKS G.A. The isoelectric points of solid oxides, solid hydroxides, and aqueous hydroxo complex systems. Chemical Reviews 65, 177, 1965.

21. DANESHVAR N., ABER S., SEYED DORRAJI M.S., KHATAEE A.R., RASOULIFARD M.H. Photocatalytic degradation of the insecticide diazinon in the presence of prepared nanocrystalline $\mathrm{ZnO}$ powders under irradiation of UV-C light. Separation and Purification Technology 58, 91, 2007.

22. KHATAEE A.R., ZAREI M., ASL S.K. Photocatalytic treatment of a dye solution using immobilized $\mathrm{TiO}_{2}$ nanoparticles combined with photoelectro-Fenton process: optimization of operational parameters. Journal of Electroanalytical Chemistry 648, 143, 2010.

23. BEHERA S., OH S., PARK H. Sorptive removal of ibuprofen from water using selected soil minerals and activated carbon. International journal of environmental science and technology 9, 85, 2012.

24. SHEIKHNEJAD-BISHE O., ZHAO F., RAJABTABARDARVISHI A., KHODADAD E., HUANG Y. Precursor and Reaction Time Effects in Evaluation of Photocatalytic Properties of $\mathrm{TiO}_{2}$ Nanoparticles Synthesized via Low Temperature. Int. J. Electrochem. Sci 9, 3068, 2014. 